\title{
Evidence for genetic homogeneity in autosomal recessive generalised myotonia (Becker)
}

\author{
Manuela C Koch, Kenneth Ricker, Michael Otto, Friedrich Wolf, Barbara Zoll, \\ Claudius Lorenz, Klaus Steinmeyer, Thomas J Jentsch
}

\begin{abstract}
Generalised myotonia Becker (GM) is an autosomal recessively inherited muscle disorder. Affected subjects exhibit myotonic muscle stiffness in all skeletal muscles with marked hypertrophy in the legs. A transient muscle weakness is particularly pronounced in the arms and hands and is a typical symptom of the disorder. Recently, we showed complete linkage of the disorder GM to the gene (CLCN1) coding for the skeletal muscle chloride channel CLC-1 and the TCRB gene on chromosome 7 in German families. In the study presented here we performed linkage analysis on 14 new GM families. The GM locus was again completely linked to both the CLCN1 and the TCRB gene in all families with a combined lod score of $Z=9 \cdot 26$ at a recombination fraction of $\theta=0 \cdot 00$. This confirms our previous data and supports the hypothesis that GM is a genetically homogeneous disorder. The previously detected $T$ to $G$ missense mutation is found on $15 \%$ of the 66 GM chromosomes counted so far.

(F Med Genet 1993;30:914-17)
\end{abstract}

Following the description by Thomsen ${ }^{1}$ of an autosomal dominant myotonic disorder in 1876 , subsequent reports classified all patients with non-dystrophic human myotonia as having Thomsen disease. In 1948 Thomasen $^{2}$ discussed the possibility of a non-dystrophic myotonic disorder inherited in an autosomal recessive manner. It was Becker, however, who, using pedigree analysis in 104 German families, showed convincingly that inheritance of a human myotonia was compatible with autosomal recessive transmission. ${ }^{34}$ Becker named the disorder generalised myotonia (MIM 255700) to distinguish it from the well recognised autosomal dominant myotonia congenita (Thomsen disease, MIM 160800).

Generalised myotonia (GM) is a non-dystrophic myotonic disorder of the skeletal muscle with an estimated prevalence of 1:50000 and a heterozygote frequency of about $1 \%$ in the German population. ${ }^{4}$ Data from other populations are sparse and are limited to single cases and family reports. ${ }^{5-9}$

Symptoms of GM may appear as early as 2 years of age or as late as the beginning of the third decade. Most patients notice symptoms primarily in the leg muscles. Within a few years the stiffness is also experienced in the arms, the neck, and the facial muscles. Many patients exhibit marked hypertrophy of the thigh, gluteal, and calf muscles. In a number of patients myotonic stiffness is followed by a transient weakness, which is particularly pronounced in the arms and hands. ${ }^{10}$ Electromyographic investigation shows abundant myotonic discharges in all skeletal muscles. There are no pathognomonic structural abnormalities in the muscle fibres and muscle biopsy is therefore not useful to aid diagnosis.

The basis of the myotonic symptoms is a hyperexcitability of the muscle fibre membrane. In GM this hyperexcitability is thought to be based on a reduced sarcolemmal chloride conductance. ${ }^{1112}$ Studies of the mouse ADR phenotype and genotype, a recessively inherited myotonic mutant, which is considered to be a realistic animal model for human myotonia with an autosomal recessive mode of inheritance, gave the first clues to the molecular identification of the human GM gene. ${ }^{13-17}$ In a second step the major mammalian skeletal muscle chloride channel CLC-1 was cloned. ${ }^{18}$ A transposon, which destroys the coding sequence for several membrane spanning domains of the skeletal muscle chloride channel in ADR mice, was identified.$^{19}$ In addition this gene was mapped to mouse chromosome 6 between marker genes Tcrb and Hox 1.1, both of which are located in human chromosome 7 . Subsequently, a partial human CLC-1 cDNA clone (pL7) derived from the skeletal muscle chloride channel gene (CLCN1) was localised to human chromosome 7q32-qter and was shown to be tightly linked to TCRB. ${ }^{20}$ Tight linkage of these two loci to the GM gene was found in seven German families. A mutation in the CLCN1 gene was also identified, a phenylalanine to cysteine substitution in the putative transmembrane domain D8 of the channel protein.

The present study was undertaken to collect further data in additional well defined GM families in order to determine whether the disease shows allelic or non-allelic genetic heterogeneity.

\section{Materials and methods}

FAMILY STUDIES

Clinical and genetic studies were performed in 14 well defined German GM families (78 subjects) comprising 25 affected (aged 3 to 70 years) and 21 unaffected offspring. All family members were personally seen by two of the authors (MCK, KR). An EMG in at least one affected family member was performed. In addition 12 isolated patients with the diagnosis $\mathrm{GM}$ were screened for the rare $\mathrm{pL} 7 / \mathrm{Nsi}$ I allele A3, representing the $T$ to $G$ missense muta- 
Table 1 Probes and polymorphisms used in the analysis.

\begin{tabular}{|c|c|c|c|c|}
\hline Locus/probe & Polymorphism & $\begin{array}{l}\text { Allele } \\
\text { sizes }\end{array}$ & $\begin{array}{c}\text { Allele } \\
\text { frequencies }\end{array}$ & PIC \\
\hline $\mathrm{CLCN1} / \mathrm{pL} 7$ & $\begin{array}{l}\text { NsiI } \\
\text { AvaII } \\
\text { Sau96I }\end{array}$ & $\begin{array}{l}\text { A1 }>30 \mathrm{~kb} \\
\text { A2 } 21 \mathrm{~kb}, 17 \mathrm{~kb} \\
\text { A3 } 21 \mathrm{~kb}, 10 \mathrm{~kb}, 7 \mathrm{~kb} \\
\text { A1 } 15 \mathrm{~kb} \\
\text { A2 } 12 \mathrm{~kb} \\
\text { A1 } 22 \mathrm{~kb} \\
\text { A2 } 18 \mathrm{~kb}\end{array}$ & $\begin{array}{l}0.6 \\
0 \cdot 4 \\
T>G \\
0 \cdot 2 \\
0 \cdot 8 \\
0 \cdot 18 \\
0 \cdot 82\end{array}$ & $\begin{array}{l}0 \cdot 37^{2} \\
0 \cdot 27^{2} \\
0 \cdot 25^{26}\end{array}$ \\
\hline TCRB & PCR type & $\begin{array}{l}7 \text { alleles* } \\
240-280 \text { bp } \\
\text { A1-A4 } \\
\text { A5 } \\
\text { A6 } \\
\text { A7 }\end{array}$ & $\begin{array}{l}0.165 \\
0.01 \\
0.32 \\
0.01\end{array}$ & $0 \cdot 76^{23}$ \\
\hline
\end{tabular}

* Data from this study.

\section{LINKAGE ANALYSIS}

Two point and multipoint lod scores were calculated by the method of maximum likelihood and the computer program LINKAGE 5.04, updated by Ott. ${ }^{24}$ Autosomal recessive inheritance with complete penetrance was assumed for GM.

HETEROGENEITY TEST

There are three alternative hypotheses in the HOMOG programs: $\mathrm{H}_{0}, \mathrm{H}_{1}$, and $\mathrm{H}_{2} \cdot{ }^{24}$ The hypothesis in favour of heterogeneity $\left(\mathrm{H}_{2}\right)$ assumes two family sets in the study, one that does show linkage to the marker locus tested and one that does not. The homogeneity hypothesis $\left(\mathrm{H}_{1}\right)$ assumes that the relationship between the disease locus and marker locus is the same in all families studied. The null hypothesis $\left(\mathrm{H}_{0}\right)$ assumes both homogeneity and absence of linkage. The related program HOMOG2 divides the families under study into two categories which both show linkage but to different markers on the chromosome.

\section{Results}

CLINICAL FINDINGS

All subjects classified as affected fulfilled the diagnostic criteria outlined in the introduction. Four families came from the same remote rural area and parental consanguinity could not be excluded. The remaining 10 families were not related. In 12 families both parents were included in the linkage analysis and in two families only one parent was available.

An EMG was performed on 11 obligate heterozygote parental couples. In one family both parents and in a second family the mother exhibited discrete myotonic discharges. Of the 21 unaffected sibs, 16 were shown to be heterozygous gene carriers by haplotype information. Of the 37 affected subjects 27 showed transient weakness, in five patients the examination was equivocal, and in five patients no weakness was detected.

The cycling conditions $(30 \times)$ were $60^{\circ} \mathrm{C}$, and $72^{\circ} \mathrm{C}$ for one minute, respectively. PCR products were electrophoresed on $6 \%$ denaturing polyacrylamide gels and dried gels were exposed on radiographic film. Polymorphism in the size of PCR products was determined in 90 unrelated German controls. Seven alleles were found, the most common allele being allele A6 of approximately $244 \mathrm{bp}$ (table 1).

Table 2 Summary of the lod score results between chromosome $7 q$ markers and generalised myotonia Becker (GM).

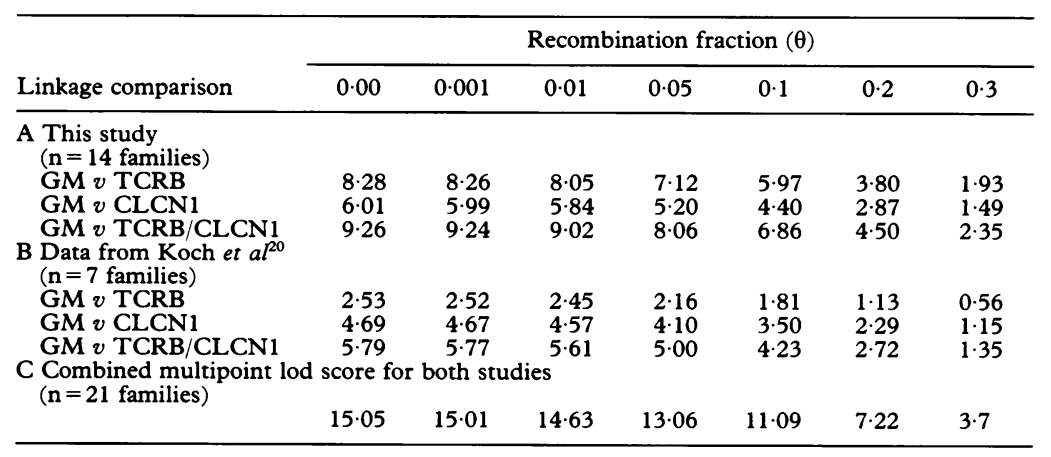

\section{LINKAGE ANALYSIS}

The lod scores from the two point and multipoint analyses at a recombination fraction of $\theta=0.00-0.30$ are summarised in table 2 . All parents were typed with both gene probes and the informative polymorphisms were used to type the offspring. No recombination was found between GM and the markers applied. Each gene probe separately, and the combined haplotype of the two, were tightly linked to GM with a maximum lod score of $Z=+9 \cdot 26$ at $\theta=0.00$ (support interval $0.00-0.04$ ). The combined multipoint lod score of $21 \mathrm{GM}$ families, comprising $14 \mathrm{GM}$ families from this study and seven GM families from our previous study, resulted in an overall score of $Z=+15.05$ at $\theta=0.00$ (support interval 0.00 0.02 ). No preferential haplotype segregated with the disease in the different families. Pedigrees and linkage data of two representative German GM families are shown in the figure.

The allele A3 (pL7/NsiI), representing a T 
to $G$ point mutation, was found in five families. All affected family members were compound heterozygotes, having in addition an as yet unidentified second mutation.

Of the 12 well defined isolated GM patients two exhibited this missense mutation on one chromosome. Together with the two previously reported families ${ }^{20}$ this mutation was found in $15 \%$ of the $66 \mathrm{GM}$ chromosomes counted.

\section{HETEROGENEITY TESTS}

The lod scores for each family, obtained from the LINKAGE results, were used in the HOMOG programs. Analysis of the data under the assumption of heterogeneity $\left(\mathrm{H}_{2} v\right.$ $\mathrm{H}_{1}$ ) gave negative results (table $3 \mathrm{~A}$ ): $\chi^{2}$ values for heterogeneity are not significant, the maximum $\ln$ likelihood values are not different for the two hypotheses, and therefore the $\alpha$ values
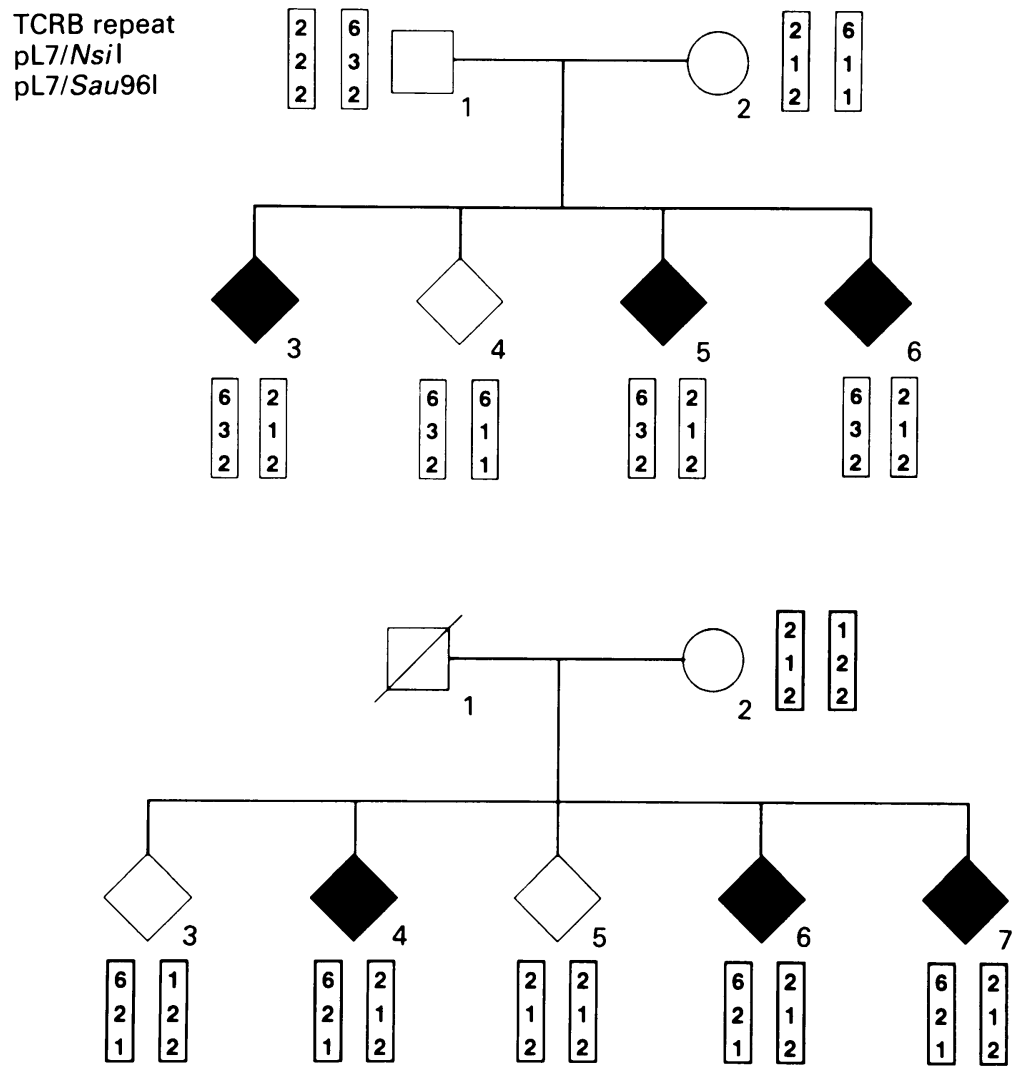

Genotypes produced by the dinucleotide repeat polymorphism in the TCRB gene and the probe pL7 (partial CLC-1 cDNA) in two families. Alleles are as described in the probe 1 .

Table $3 A$ Tests of linkage homogeneity (HOMOG, version 3.0) in 21 GM families for loci TCRB and CLCN1.

\begin{tabular}{|c|c|c|c|c|c|c|c|}
\hline \multirow[b]{2}{*}{ Tests } & \multicolumn{4}{|c|}{ CLCN1 } & \multicolumn{3}{|c|}{ TCRB } \\
\hline & $\mathrm{df}$ & $\chi^{2}$ & $\operatorname{Max} \ln (\mathrm{L})$ & $\alpha$ & $\chi^{2}$ & $\operatorname{Max} \ln (\mathrm{L})$ & $\alpha$ \\
\hline $\begin{array}{l}\mathrm{H} 2 v \mathrm{H} 1 \text { (heterog) } \\
\mathrm{H} 1 v \text { H0 linkage } \\
\mathrm{H} 2 v \text { H0 total }\end{array}$ & $\begin{array}{l}1 \\
1 \\
2\end{array}$ & $\begin{array}{l}0 \cdot 0 \\
49 \cdot 2 \\
49 \cdot 2\end{array}$ & $\begin{array}{c}24 \cdot 62 \\
24 \cdot 62 \\
(0)\end{array}$ & $\begin{array}{l}1.0 \\
(1) \\
(0)\end{array}$ & $\begin{array}{r}0 \cdot 0 \\
49 \cdot 8 \\
49 \cdot 8\end{array}$ & $\begin{array}{c}24 \cdot 89 \\
24 \cdot 89 \\
(0)\end{array}$ & $\begin{array}{l}1 \cdot 0 \\
(1) \\
(0)\end{array}$ \\
\hline
\end{tabular}

Table 3B Tests for linkage homogeneity (HOMOG2, version 2.75) in 21 GM families for linkage to two different loci, TCRB and CLCN1.

\begin{tabular}{lcccccc}
\hline Tests & $\mathrm{df}$ & $\chi^{2}$ & $\operatorname{Max} \ln (\mathrm{L})$ & $\alpha$ & $\theta_{1}$ & $\theta_{2}$ \\
\hline H2 $v$ H1 (heterog) & 2 & 0.0 & 49.5 & 1.0 & 0.0 & 0.0 \\
H1 $v$ H0 linkage & 1 & 99.0 & 49.5 & $(1)$ & 0.0 & 0.0 \\
H2 $v$ H0 total & 3 & 99.0 & $(0)$ & $(0)$ & $(0.5)$ & $(0.5)$ \\
\hline
\end{tabular}

are $1 \cdot 0$. The computer program HOMOG2 was used to perform a statistical A test for the presence of two sets of families, one set linked to TCRB and one set linked to CLCN1. The likelihood ratios for heterogeneity were calculated under the hypothesis of heterogeneity versus homogeneity. The hypothesis of linkage with only one family type $\left(\mathrm{H}_{1}\right)$ is supported (table 3B), while $\mathrm{H}_{2}$ (= heterogeneity) is rejected $\left(\chi^{2}=0 \cdot 00\right)$. The approximate $95 \%$ confidence interval presented by the HOMOG program is $\theta=0.00-0.08(\alpha=0.55-1.00)$ for CLCN 1 and $\theta=0.00-0.04(\alpha=0.80-1.00)$ for TCRB. The $95 \%$ confidence interval for the A test performed using HOMOG2 includes the region from $\theta=0.00-0.02(\alpha=0.05-1 \cdot 00)$.

\section{Discussion}

The results of the present study show linkage between the disorder GM and the CLCN1 gene, coding for the skeletal muscle chloride channel CLC-1, and the TCRB gene on the long arm of human chromosome $7 . .^{190}$ The data thus confirm our recent results for linkage in this chromosomal region in seven GM families and extend the study to $21 \mathrm{GM}$ families in total.

Our pooled data provide no evidence for a model with two different loci independently causing the disease, either on different chromosomes or in the same chromosomal region. The latter situation was shown for retinitis pigmentosa on the short arm of the X chromosome. ${ }^{27}$ The homogeneity data for GM are in agreement with the clinical picture for the disorder, which is quite uniform and shows no extensive intra- or interfamilial variability. This does not, of course, exclude mutational heterogeneity at the actual GM disease locus. This does exist since the identified missense mutation is present in a homozygous state in only one family, the heterozygous parents being third cousins. ${ }^{20}$ The remaining eight affected subjects exhibit the mutation on one chromosome only, which suggests compound heterozygosity.

Autosomal dominant myotonia congenita (MC, Thomsen disease) has also been shown to be linked to the CLCN1 and TCRB genes and a mutation has been identified. ${ }^{202328}$ These data suggest that the two phenotypes which appeared at first to represent separate entities are, in fact, allelic disorders. Therefore the two diseases are now classified as muscle chloride channel disorders, in a similar manner to the designation of the different phenotypes in muscle sodium channelopathies. ${ }^{29}$

Data from the clinical and genetic studies of Thomasen $^{2}$ and Becker ${ }^{4}$ suggested that about $80 \%$ of the reported MC families do have the autosomal recessive form of GM. The diagnosis of GM as opposed to MC should not be difficult in typically affected subjects. The classical GM patient will exhibit a transient muscle weakness and a family history of autosomal recessive inheritance. ${ }^{30}$ Our study showed that transient muscle weakness is a good diagnostic criterion which differentiates GM from MC. About $75 \%$ of the affected subjects studied have this symptom. However, 
in isolated cases without transient muscle weakness it may not be possible to make a distinction between GM and Thomsen disease.

The muscle chloride channel disorders, GM and $M C$, have to be added to the increasing number of diseases that are sometimes dominantly and sometimes recessively inherited, even though they are linked to the same gene locus and show mutations within the same gene, as shown recently for hypoparathyroidism and retinitis pigmentosa. ${ }^{3132}$ Future studies into these chloride channel disorders may show a possible basis for the differences in inheritance. The reported translation mutation (phe to cys) in the CLCN1 protein product probably results in a null allele with respect to the ability to participate in channel function. Since it is predicted that the gene product is a homomeric multisubunit protein in a single dose, a partial loss of functional gene product might be relatively harmless and may not change channel function; the heterozygote consequently would not show an abnormal phenotype. However, a heterozygous condition which produces an abnormal gene product of a dominant negative type which interferes with the expression of the normal allele will have a deleterious effect, such as alterations in the physical properties of channel function, and thus the phenotype will be changed.

The identification of additional mutations in the CLCN1 gene might therefore allow correlations between specific mutations, genotypes, and phenotypes. However, many mutations may not be observed in sufficient numbers to allow definition of their precise phenotypes, nor to draw conclusions for altered channel function.

This paper is dedicated to Professor Dr Dr Peter Emil Becker on the occasion of his 85th birthday. The authors gratefully acknowledge the cooperation of all the probands and their families. We are indebted to G Grahmann and G Panzner for technical assistance. This work was supported by the Deutsche Forschungsgemeinschaft (DFG), the Muscular Dystrophy Association (MDA), and the Deutsche Gesellschaft Bekämpfung der Muskelkrankheiten (DGBM).

1 Thomsen J. Tonische Krämpfe in willkürlich beweglichen Muskeln in Folge von ererbter psychischer Disposition (Ataxia muscularis?). Arch Psychiatr 1876;6:702-18.

2 Thomasen E. Myotonia. A clinical and heredobiologic investigation. Danmark: Universitetsforlaget i Aarhus, 1948.

Becker PE. Die Heterogenie der Myotonien. Excerpta Medica International Congress Series $1961 ; 32 \cdot \mathrm{D} 93-4$

4 Becker PE. Myotonia congenita and syndromes associated with myotonia. In: Topics in Human Genetics. Stuttgart: Georg Thieme Verlag, 1977.

5 Harper PS, Johnston DM. Recessively inherited myotonia congenita. $\mathcal{F}$ Med Genet 1972;9:213-15.

6 Prabhakar S, Chopra JS. Autosomal recessive generalised myotonia (a case report). $\mathcal{f}$ Assoc Physicians India 1981;29:791-3.

7 Sun SF, Streib EW. Autosomal recessive generalised myotonia. Muscle Nerve 1983;6:143-8.

8 Yonekura J, Yazaki S, Takahashi Y, et al. A case of Becker type congenital myotonia with myalgia. Rinsho Shinkeigaku 1989;29:1140-3.

9 Zellweger H, Pavone L, Biondi A, et al. Autosomal recessive generalized myotonia. Muscle Nerve 1980;3:176-80.

10 Ricker K, Haass A, Hertel G, Mertens HG. Transient muscular weakness in severe recessive myotonia congenita. F Neurol 1978;218:253-62.

11 Lipicky BJ, Bryant SH, Salmon JH. Cable parameters, sodium, potassium, chloride, and water content, and potassium efflux in isolated external intercostal muscle of potassium efflux in isolated external intercostal muscle of f Clin Invest 1971;50:2091-103.

12 Rüdel R, Ricker K, Lehmann-Horn F. Transient weakness and altered membrane characteristic in recessive generalized myotonia (Becker). Muscle Nerve 1988;11:202-11.

13 Jockusch H. Molecular aspects of myotonia: the ADR mouse as a model. $\mathcal{f}$ Neurol Sci 1990;98(suppl):9.

14 Rüdel R. The myotonic mouse - a realistic model for the study of human recessive generalized myotonia. Trends Neurosci 1990;13:1-3.

15 Füchtbauer EM, Reininghaus J, Jockusch H. Developmental control of the excitability of muscle: transplantation experiments on a myotonic mouse mutant. Proc Nat Acad Sci USA 1988;85:3880-4.

16 Mehrke G, Brinkmeier $H$, Jockusch $H$. The myotonic mouse mutant adr: electrophysiology of the muscle fiber. Muscle Nerve 1988;11:440-6.

17 Reininghaus J, Füchtbauer EM, Bertram K, Jockusch H. The myotonic mouse mutant adr: physiological and histochemical properties of muscle. Muscle Nerve 1988;11:433-9.

18 Steinmeyer K, Ortland C, Jentsch TJ. Primary structure and functional expression of a developmentally regulated skeletal muscle chloride channel. Nature 1991;354:301-4

19 Steinmeyer K, Klocke R, Ortland C, et al. Inactivation of muscle chloride channel by transposon insertion in myotonic mice. Nature 1991;354:304-8.

20 Koch MC, Steinmeyer K, Lorenz C, et al. The skeletal muscle chloride channel in dominant and recessive human myotonia. Science 1992;257:797-800.

21 Sambrook J, Fritsch EF, Maniatis T. Molecular cloning. A laboratory manual. 2nd ed. New York: Cold Spring Harbor Laboratory Press, 1989.

22 Litt M. PCR of TG microsatellites. In: McPherson MJ, Quirke P, Taylor GR, eds. PCR, a practical approach. Oxford: Oxford University Press, 1991

23 Abdalla JA, Casley WL, Cousin HK, et al. Linkage of Thomsen disease to the T-cell-receptor beta (TCRB) locus on chromosome $7 \mathrm{q} 35$. Am $\mathcal{f}$ Hum Genet 1992;51:579-84.

24 Ott J. Analysis of human genetic linkage. Baltimore: Johns Hopkins University Press, 1991.

25 Ott J. Linkage analysis and family classification under heterogeneity. Ann Hum Genet 1983;47:311-20.

26 Wolf F, Koch MC, Steinmeyer K, Jentsch TJ. A Sau96I RFLP at the human skeletal muscle chloride channel locus (CLCN1). Hum Mol Genet (submitted).

27 Ott J, Bhattacharya S, Chen JD, et al. Localizing multiple $\mathrm{X}$ chromosome-linked retinitis pigmentosa loci using multilocus homogeneity tests. Proc Natl Acad Sci USA multilocus hom

28 George AL, Crackower MA, Abdalla JA, et al. Molecular basis of Thomsen's disease (autosomal dominant myotonia congenita). Nature Genet 1993;3:305-10.

29 Ptacek LJ, Johnston KJ, Griggs RC. Genetics and physiology of the myotonic muscle disorders. $N$ Engl $f$ Med 1993;328:482-9.

30 Becker PE. Heterozygote manifestation in recessive generalized myotonia. Hum Genet 1979;6:325-9.

31 Parkinson DB, Thakker RV. A donor splice site mutation in the parathyroid hormone gene is associated with autosomal recessive hypoparathyroidism. Nature Genet 1992;1:149-52.

32 Rosenfeld PJ, Cowley GS, McGee TL, et al. A null mutation in the rhodopsin gene causes rod photoreceptor mutation in the rhodopsin gene causes rod photoreceptor
dysfunction and autosomal recessive retinitis pigmentosa. Nature Genet 1992;1:209-13. 